\title{
Violencia sin tregua. Hondureños en la región del Golfo de México
}

\author{
Violence without truce. Hondurans in the Gulf of Mexico región
}

\author{
María Teresa Rodríguez \\ Centro de Investigaciones y Estudios \\ Superiores CIESAS-México \\ mtrguez@ciesas.edu.mx
}

\begin{abstract}
Resumen
Los estados mexicanos de Chiapas y Tabasco han estado ligados desde hace décadas al flujo migratorio centroamericano, a causa de la movilidad laboral transfronteriza. Sin embargo, hoy en día la diversificación de las zonas receptoras en México hace necesaria la observación de estos flujos de tránsito o asentamiento migratorio que atañen a nuevos contextos. Tal es el caso del estado de Veracruz, entidad federativa que forma parte del corredor del Golfo de México que conecta a la frontera sur mexicana con la frontera norte en su vertiente oriental. Veracruz, al igual que otros estados del país, se ha convertido en destino no planeado -temporal o definitivo- para migrantes centroamericanos -especialmente hondureños-. El presente artículo es resultado de las reflexiones generadas a partir de observaciones y entrevistas efectuadas en localidades del centro de la entidad veracruzana. Se retoma la tipología de la violencia propuesta por Burgois (2005) para contextualizar las diferentes formas y expresiones de violencia que padecen los migrantes indocumentados en tránsito y/o en residencia temporal o definitiva en las localidades de estudio. Dichas formas de violencia se enmarcan en las condiciones estructurales de discriminación y estigmatización vinculadas a la condición de "ilegalidad" de los migrantes.
\end{abstract}

Palabras Claves: Violencia; hondureños; migración; Centroamérica; Veracruz

\begin{abstract}
The Mexican states of Chiapas and Tabasco have been linked for decades to Central American migrations, largely due to cross-border labor mobility. Nevertheless, today the diversification of receiving areas in Mexico requires attention to how such dynamics of mobility, settlement or transit affect these new contexts. Such is the case of the state of Veracruz, which is part of the corridor of the Gulf of Mexico which connects the southern Mexican border with the northern border on its eastern slope. Veracruz, like other states in the country, has emerged as an unplanned destination state - both as a temporary or permanent place of residence - for Central American migrants, especially Hondurans. This article consists of reflections generated from observations and interviews carried out in localities of the center of Veracruz. The typology of violence proposed by Burgois (2005) is employed to contextualize the different forms and expressions of violence experienced by undocumented migrants in transit, and temporary or permanent residents in the studied locales. These forms of violence partially constitute the structural conditions of discrimination and stigmatization linked to the migrants' condition of "illegality".
\end{abstract}

Key Words: Violence; Hondurans; migration; Central America; Veracruz 


\section{Introducción}

Durante los últimos años, el volumen y la composición del flujo migratorio centroamericano por México con dirección a Estados Unidos, ha tomado relevancia en la opinión pública. Llama la atención la persistencia de este fenómeno, no obstante los riesgos y dificultades que enfrentan los migrantes. Dichos obstáculos son de diversa índole: los peligros propios de un viaje en la clandestinidad y con escasos recursos económicos, condiciones que los obligan a caminar largos tramos atravesando ríos, selvas, cañadas y desiertos, a viajar ocultos y hacinados en camiones o tráileres, o a bordo de trenes donde se exponen al acoso y agresiones de delincuentes. Se arriesgan a todo ello para evadir las medidas impulsadas por las políticas de contención de los gobiernos mexicano y norteamericano. Dichas medidas conllevan amplias probabilidades de aseguramiento y deportación para los migrantes sin documentos.

Si bien existe la posibilidad de solicitar el estatus de refugiado ante la Comisión Mexicana de Ayuda a Refugiados (COMAR), demostrando que la vida, seguridad o libertad han sido amenazadas en el país de origen (lo cual es el caso de muchos de ellos), solamente una porción reducida de migrantes centroamericanos lo intenta. Y muchos de quienes lo hacen terminan desistiendo, debido a los escollos burocráticos del proceso. Entre 2002 y 2011, solicitaron la condición de refugiados 5255 personas, de las cuales sólo el 23\% obtuvo dicho reconocimiento. Honduras, El Salvador, Colombia y Guatemala figuraron como los países de procedencia del mayor número de peticiones (Cobo y Fuerte, 2012). Sin embargo, sólo en año 20168.781 extranjeros solicitaron asilo; la mayoría de ellos de Honduras y El Salvador, países azotados por la violencia y la pobreza (Llanes, 2017).

Durante el periodo del presidente Felipe Calderón Hinojosa (de 2006 a 2012), se incrementó de forma alarmante la violencia hacia los migrantes y se evidenciaron las condiciones extremadamente riesgosas de su trayecto (Calderón, 2016). A partir del año 2014, se puso en marcha el Plan Frontera Sur y desde entonces las autoridades mexicanas han colaborado con Estados Unidos en la contención de la migración centroamericana mediante las deportaciones de migrantes. Este programa se planteó como un programa de atención de los flujos migratorios en la región, pero está dirigido en los hechos a la contención de la migración (Castañeda, 2015:8). Tan sólo en el año 2016, el Instituto Nacional de Migración deportó 147.370 migrantes; $93 \%$ procedentes del Triángulo Norte Centroamericano (Honduras, Guatemala y El Salvador) (Llanes, 2017).

No obstante, el recrudecimiento de las políticas antiinmigrantes (tanto del gobierno mexicano como del gobierno estadounidense a partir de la administración de Barack Obama y de las medidas aún más severas iniciadas por Donald Trump), actualmente tiene lugar a un proceso de fortalecimiento de México como lugar de destino -temporal o definitivo- para los migrantes centroamericanos en situación migratoria irregular. Frente a las dificultades para llegar a Estados Unidos, destinos no planeados de la ruta mexicana se adoptan para asentarse de forma transitoria o por tiempo indefinido, especialmente por parte de individuos procedentes de Guatemala, Honduras y El Salvador (Fernández y Rodríguez, 2016).

Por otra parte, para evitar los riesgos de las deportaciones se exploran nuevas rutas con dirección hacia el norte de México; se han puesto en práctica itinerarios más complejos y costosos. Por ejemplo, travesías marítimas desde El Salvador o Guatemala hacia las costas mexicanas del Pacífico oaxaqueño, de donde los migrantes se desplazan por tierra hacia los estados de Sonora y Baja California, en la frontera con Estados Unidos. La diversificación de rutas y de zonas receptoras, hace necesaria la observación de los 
flujos de tránsito y asentamiento que atañen a nuevos contextos dentro del territorio mexicano.[1] Veracruz, entidad federativa que forma parte del corredor del Golfo de México, conecta a la frontera sur mexicana con la frontera nororiental en el estado de Tamaulipas; al igual que otros estados del país, se ha convertido en destino no planeado -temporal o definitivopara migrantes centroamericanos, especialmente hondureños.

Las formas de violencia hacia los migrantes centroamericanos en situación migratoria irregular a su paso por México han sido ampliamente documentadas por parte de la academia, la prensa y organismos de la sociedad civil, al grado tal que son considerados como el grupo migrante más vulnerable del Hemisferio Occidental (Rodríguez H., 2016; Rodríguez E., 2016 y Calderón, 2016). A pesar de ello, es notable la escasez de estudios etnográficos sobre la trayectoria y/o inserción de migrantes indocumentados a niveles locales en México, más allá de los trabajos realizados en la frontera sur (donde existe una dinámica transfronteriza relacionada con el mercado laboral). De igual manera, falta un acercamiento más profundo a la forma de vida de los migrantes en condición de transitoriedad permanente: aquellos que no saben a dónde ir porque han renunciado al "sueño americano" y no desean volver a su país de origen; que adaptan sus metas y planes día con día, pernoctando en vagones de tren en desuso, en cuartos de vecindad insalubres o en refugios improvisados.

El presente artículo es resultado de las reflexiones generadas a partir de observaciones y entrevistas realizadas en localidades del centro de la entidad veracruzana. Realicé alrededor de cuarenta entrevistas abiertas e informales a migrantes indocumentados (hondureños en su gran mayoría), específicamente en las ciudades de Xalapa, la capital del estado, así como en los municipios de Chiconquiaco, Córdoba, Orizaba, Fortín y Amatlán de los Reyes. La mayoría de los entrevistados son jóvenes y llegaron a México con la intención de transitar hacia Estados Unidos, pero frente a las barreras para conseguir este objetivo se encuentran "atrapados en la movilidad" (Arriola, 2012), puesto que el regreso a su país tampoco es una opción dadas las circunstancias de inseguridad y penuria que los impulsaron a salir.

Llama la atención la enorme variabilidad de situaciones en términos de la temporalidad de su estancia en la entidad y/o el país. Mientras algunos están estrictamente de paso, decididos a continuar el viaje hacia la frontera norte -son aquellos que no han perdido la esperanza de cruzar- otros llevan semanas, meses o incluso años en movilidad permanente o asentados de manera más o menos estable en territorio mexicano. Todos, sin embargo, cuentan en su haber con un acervo de experiencias violentas que han marcado su trayectoria migratoria. Viajar sin documentos da lugar a la total desprotección por parte de los estados nacionales de tránsito o destino, y en consecuencia los migrantes se convierten en personas altamente vulnerables a todo tipo de cuestionamientos, abusos y agresiones (Alvarez, 2011: 11).

La condición de clandestinidad y la alta movilidad de los migrantes indocumentados representan un reto para el trabajo de investigación etnográfico. $\mathrm{Su}$ condición de irregularidad migratoria y el contexto de violencia y transitoriedad en que se desenvuelven, hacen particularmente difícil el establecimiento de relaciones y vínculos personales profundos. La ciudad de Xalapa fue escenario de la mayor parte de las entrevistas que realicé para esta investigación. Llevé a efecto observaciones en lugares clave de la vía pública, lo cual me hizo posible entender algo de la lógica de la movilidad y/o permanencia en la ciudad. La observación in situ fue una manera de aprehender el movimiento; me permitió el acercamiento reiterado a migrantes que se colocaban con cierta regularidad en determinados puntos de la ciudad, solicitando 
ayuda económica a peatones y automovilistas. Dichos acercamientos me permitieron verificar las primeras versiones de sus relatos en relación con sus planes, objetivos y actividades cotidianas.

A lo largo de dos años (2015 y 2016) me detuve particularmente en un crucero de la vía pública ubicado cerca de las vías del tren, en la Colonia Jardines de Xalapa, donde muy a menudo encontraba a jóvenes y/o familias hondureñas solicitando ayuda a las personas que transitaban por ahí, a pie o en automóvil. No obstante, a pesar de haber establecido relaciones sólidas con algunos de mis entrevistados, no logré profundizar en la observación etnográfica de sus espacios privados, altamente cambiantes e inestables. En repetidas ocasiones me encontré con cierta reticencia y desconfianza por parte de personas migrantes a quienes trataba de entrevistar. Con razón, muchos migrantes indocumentados tienden a desconfiar de los otros y se cierran herméticamente, preocupándose por la vigilancia del Estado y la posibilidad de una deportación (Shoshan, 2015: 2).

El estatus migratorio determina el ejercicio o ausencia de derechos desde el momento en que el individuo sale del país de origen, y es factor determinante durante todo el trayecto y en el lugar de destino. La movilidad de las personas implica relaciones espaciales a través de líneas de demarcación política. Esta jerarquización de los espacios se vincula con la asignación de derechos diferenciales para diferentes categorías de personas. Como señala De Genova (2002, 2004), la condición de "ilegalidad" es un estatus jurídico que implica una relación con el Estado; por lo tanto la categoría de migrante "ilegal" es eminentemente política. Dicha "ilegalidad" se relaciona con la vigilancia sobre el cuerpo y los movimientos de las personas, y genera un estigma que las excluye de determinados marcos sociales. Ser víctima de un estigma (Goffman, 2001) entraña un posicionamiento altamente vulnerable. En el caso de los migrantes sin documentos, a la inseguridad vinculada con la no ciudadanía -como sujeto de derecho- se agrega su inserción en un continuum de actos violentos.

Bourgois (2005) plantea que para el estudio de la violencia es preciso entenderla no como un acto sino como un continuo, es decir, como una suma de actos que tienen lugar tanto a nivel estructural, como político, simbólico y cotidiano. Ferrándiz y Feixa coinciden con este autor al señalar la dimensión multifacética de la violencia: "aunque se tienda a definir la violencia como el uso agresivo de la fuerza física por parte de individuos o grupos en contra de otros, hay otras formas de agresividad no física (verbal, simbólica, moral) que suelen hacer más daño" (2004: 160). Dichas dimensiones no son excluyentes; la tarea del etnógrafo es "desenredar los hilos de la violencia" (Feixa y Ferrándiz, 2005: 213), mostrar su carácter procesual y las tensiones y entrecruces que se dan entre las diferentes formas y actos violentos.

\section{Transitar sin papeles: un continuum de violencia}

El antropólogo norteamericano Philippe Burgois (2005) desarrolla el concepto de continuum de violencia, para explicar que todo acto de violencia se encuentra vinculado a otros. Se trata de procesos que se explican en sus conexiones con el contexto espacial y temporal en que se producen. Es por ello preciso tomar en cuenta las circunstancias socio-culturales en las que se origina la violencia, así como las historias personales de quienes la padecen o la ejercen. Los migrantes indocumentados en tránsito y/o "atrapados en la movilidad" son supeditados a una pluralidad de actos violentos desde su lugar de origen, durante el trayecto y en su destino temporal o definitivo. Sus vidas se encuentran siempre en el límite, y la violencia hacia ellos se encuentra socialmente naturalizada, "se encarna en los cuerpos, en las subjetividades y 
cotidianidades de los sujetos" (Porraz, s/f: 4).

Burgois establece una tipología de la violencia que resulta útil para contextualizar las diferentes formas y expresiones de violencia que padecen los migrantes indocumentados en tránsito y/o en residencia temporal o definitiva en las localidades de estudio. Dichas expresiones no se restringen, obviamente, a estos lugares; son apenas exiguas muestras de la experiencia vivida por hombres y mujeres que transitan sin papeles por territorio mexicano, con la esperanza de encontrar un mejor horizonte de vida para ellos y sus familias.

1.1. Burgois denomina violencia estructural a la opresión política-económica crónica de desigualdad social enraizada históricamente, que incluye desde acuerdos comerciales de explotación económica internacional, hasta condiciones de trabajo abusivas y altas tasas de mortalidad infantil (2005: 14).

A lo largo de la primera década del siglo XXI, se agudizó la violencia social en Honduras, Guatemala y El Salvador. Este incremento se ha asociado a las pandillas juveniles conocidas como maras, percibidas como un problema social agudo y como las responsables de la violencia por parte de los aparatos gubernamentales y los medios de comunicación (Martel, 2007: 109). Entre los factores estructurales que propiciaron el surgimiento de las maras, se señalan entre otros: las redes transfronterizas y la emulación de las gangas o pandillas presentes en la frontera entre México y Estados Unidos desde hace más de seis décadas, así como la deportación de jóvenes de Guatemala y El Salvador desde Estados Unidos a partir de la segunda mitad de los años ochenta.

Las deportaciones de miles de jóvenes a los países del llamado Triángulo del Norte Centroamericano, tuvieron lugar en un escenario complejo de violencia, pobreza e inestabilidad política. Los jóvenes deportados se insertaron en este marco conflictivo, reproduciendo formas de organización que tenían en sus barrios en los
Estados Unidos, y conformaron las clickas o pandillas agrupadas en La Mara Salvatrucha y Barrio 18. Al mismo tiempo, se llevaba a cabo un intenso tráfico de armas que quedaron en circulación después de los conflictos en Centroamérica, y tenía lugar un repunte de la tasa de homicidios, asaltos y robos (Valenzuela, 2007: 52).

Reguillo (2007: 313-4) señala que a partir del año 2004, las maras se instalan en el "imaginario del miedo" en estos países, incrementándose su poderío simbólico para dar paso a su criminalización. Las maras se instauraron en un vacío de legitimidad y en su avance señalaron las áreas más débiles del proyecto social. Las raíces y razones que explican este fenómeno son de carácter estructural y se reflejan en la falta de oportunidades laborales, educativas y económicas. La visibilización de los jóvenes de las maras como un problema social ha permitido que se ejerzan sobre ellos formas autoritarias de violencia institucional (Nateras, 2007).

En el caso de Honduras particularmente, las condiciones estructurales de la violencia tienen un origen complejo y multicausal, relacionado con la pauperización de amplios sectores de la población y el desplazamiento de personas huyendo de los conflictos armados (Valenzuela, 2007: 51). Más de la mitad de la población hondureña vive por debajo del umbral de pobreza. Por otra parte, el país se ubica en una región vulnerable a tormentas tropicales y huracanes, sobre todo en la zona de la cuenca del Caribe. En octubre de 1998, el huracán Mitch llegó a la costa norte de Honduras causando miles de pérdidas humanas y daños equivalentes al $72 \%$ del Producto Interno Bruto (FAO, UN-HABITAT, s/f: 2).

En 2013, se registró en Honduras una tasa de 79 homicidios por cada 100000 habitantes (González, 2014: 51-55) y se señala que el nivel de inseguridad aumentó de forma significativa en el año 2014 (Pérez 
y Zechmeister, 2014: 34). Según el informe preparado por InSight Crime (2015: 47), las maras y pandillas constituyen el desafío más grande en materia de seguridad que enfrenta el país.[2] Entre las causas que han propiciado el incremento y poderío de estas organizaciones transnacionales se señalan los procesos de exclusión social, el crecimiento urbano rápido y desordenado, la migración, la presencia de drogas, la desorganización comunitaria, la cultura de la violencia $\mathrm{y}$ las familias disfuncionales. También se subraya que las políticas estatales han tenido un énfasis predominantemente represivo, el cual ha favorecido su tránsito hacia estructuras más cerradas y complejas por parte de estas organizaciones (Aguilar y Carranza, 2008: 9-31).

Una de las consecuencias de esta difícil situación es la emigración masiva de hombres y mujeres hondureños con dirección a Estados Unidos transitando por México. Muchos jóvenes escapan del peligro de ser obligados a unirse a una de las pandillas, o bien por haber pertenecido a alguna de ellas y temer las acciones represivas de la policía o de grupos contrarios.

Uno de mis entrevistados en Xalapa[3], un joven hondureño, originario de San Pedro Sula expresa que se vio obligado por las circunstancias a salir de su país:

Casi me matan en la calle a los 16 años. Me golpearon y por poco me dejan muerto. Nos encontramos con esos majes [hombres] y mi amigo salió corriendo y escapó. Todos estaban alrededor de mí, talegueándome [golpeándome], pero como yo recé mucho, vi cómo se abría el círculo alrededor mío, se abrió entonces y pude escapar. Después me dolían las piernas y me pusieron inyecciones para que no se me infectaran las heridas, tenía todo el cuerpo morado, no podía caminar. Después me recuperé y otra vez tuve problemas y por eso me tuve que salir; me acusaron de reventar [matar] a machetazos a un bato [hombre]. Pero neta [de verdad] que yo no fui, fue mi carnal [amigo] pero como estaba con él ese día, pues me empezaron a buscar las juras [policías]. Además si regreso me matan los contrarios. En la noche no puedo dormir, pensando en mi amá [madre], en mis carnalitos [hermanitos], pero allá está muy culero [feo], yo ya no regreso (Daniel, 22 años, Xalapa, 29 de abril de 2016).

De igual forma, la historia de Pablo, otro migrante hondureño procedente de Corintio, expresa las condiciones de muchos jóvenes de su país: una vida marcada por el sufrimiento y las carencias. Llegó a México con la idea de alcanzar y cruzar la frontera con Estados Unidos; unos días después de su llegada al estado de Veracruz se encontraba probando suerte en la ciudad de Xalapa. Su rostro se entristece cuando se le pregunta por su familia, responde que él no tiene a nadie en Honduras. Cuenta que su padre se encontraba vinculado a una mara y fue asesinado cuando él tenía apenas seis años de edad. Su madre se suicidó poco tiempo después, víctima de una profunda depresión. Pablo se quedó bajo el resguardo de parientes que no cuidaron bien de él ni lo enviaron a la escuela. Sobrevivió trabajando en tareas domésticas a cambio de alimentos y algunas lempiras. Para mantenerse a salvo de las pandillas, intentó pertenecer a la mara Barrio 18, pero no se sentía cómodo y desertó. Decidió emigrar a sabiendas de que no lo dejarían en paz:

Yo no quería andar igual como ellos, porque iba a llegar un momento en que los de la pandilla que no me conocían me iban a decir, "te tienes que meter a la fuerza". Y yo pensé que no iba a durar mucho porque yo no sé lo que saben hacer ellos, pensé que me van a matar en tres o cuatro días. ¿Entonces para qué me quedaba? Y como veía que muchos paisanos se iban a Estados Unidos y que pagaban muy bien, pensé: 'mejor me voy para allá', pero nunca imaginé que estuviera tan pesado el viaje, ahora no sé qué hacer ni para dónde ir (Pablo, 20 años, Xalapa, febrero de 2016). 
La violencia estructural en su país, la falta de condiciones económicas, sociales y políticas que garanticen el desarrollo y seguridad de los niños y jóvenes, impone una vida colmada de sufrimiento físico y emocional. Una temprana y constante exposición a la violencia constituye un trágico efecto de la condición de dominación; la violencia activa de la gente está a menudo dirigida contra los propios compañeros de infortunio (Burgois, 2005: 30, cit. a Bourdieu, 1997). Bajo condiciones de degradación social y ausencia de un poder estatal de mediación, la violencia se impone como un orden basado en el temor que infunde (Abarca y Sepúlveda, 2005: 146).

1.2. La segunda forma de violencia señalada por Burgois es la violencia política directa. Consiste en la construcción de violencia física y terror con objetivos definidos, administrados por las autoridades oficiales o por aquellos que se les oponen, por ejemplo, tortura policial, represión militar y resistencia armada.

En el caso de la migración indocumentada, la violencia política directa se expresa en las formas de control derivadas de la política de administración de los flujos migratorios. Como apunta Álvarez la migración irregularizada es resultado de la profundización de la inequidad sistémica, aunada a la adopción de un violento régimen de control fronterizo global. Ello da lugar a la producción de irregularidad y de sujetos criminalizados y con posibilidades de ser deportados. Las fronteras mexicanas constituyen las puertas de acceso al mayor destino migratorio del mundo por parte de poblaciones empobrecidas del "sur global". El endurecimiento de dichas fronteras resulta adverso en distintos aspectos: lejos de detenerse la migración, se incrementan las redes de tráfico de migrantes y las expresiones de violencia social y estatal ejercida contra ellos (Alvarez, 2017: 49-51).

De Génova (2004) llama la atención sobre el sentido político del término de migración irregular, aludiendo a que se trata de una construcción generada y construida por el Estado. La figura del migrante indocumentado comporta una dimensión política, en tanto refiere a determinado tipo de personas desposeídas e invisibilizadas a causa de su movilidad (Nail, 2015: 7). La ilegalidad es vivida mediante un sentimiento de "deportabilidad"; la posibilidad latente de ser removido de un determinado territorio es condición decisiva en la producción legal de la "ilegalidad". De este modo, la deportación se constituye en un mecanismo crucial de disciplina, subyugación y violencia política administrada por los Estados. La "ilegalidad" es una condición inseparable de las formas en que los migrantes son racializados $\mathrm{y}$ violentados, física $\mathrm{y}$ simbólicamente (De Genova, 2004: 164-8).

Al transitar por México, los migrantes indocumentados no solamente deben eludir la vigilancia de los agentes del Instituto Nacional de Migración, sino también de las acciones de delincuentes y grupos del crimen organizado que ejercen sobre ellos distintas formas de violencia. Hoy en día es de dominio público el tipo de experiencias violentas a que se ven expuestos: secuestros, extorsiones, maltratos físicos, hacinamientos, condiciones extremas, mutilaciones, violaciones y hasta la pérdida de la vida. Paradójicamente, algunas de las formas más seguras de viajar sin documentos, incluyen el pago por protección al crimen organizado y la participación en acciones ilegales. Por ejemplo, de acuerdo con los testimonios recopilados, para poder viajar en el tren (conocido como La Bestia) rumbo al centro del país es necesario pagar una cuota de 100 dólares por persona, bajo la amenaza de ser lanzados del convoy en movimiento si se resisten al pago de dicho "arancel". También se encuentran en riesgo de ser secuestrados por miembros de los cárteles que operan en el corredor del Golfo de México, así como en otras zonas del país.

Francisco, un guatemalteco entrevistado en Amatlán de los Reyes, Veracruz, relató que de acuerdo con su 
experiencia, la forma más segura de cruzar la frontera de México con Estados Unidos es pasar con un cargamento en la espalda, protegido por los traficantes de droga. En su primer viaje, después de una larga odisea para llegar a la frontera de Baja California (al noroeste de México), se quedó en la ciudad de Mexicali unos días, sin saber qué hacer para cruzar al país vecino, hasta que se le presentó la oportunidad:

Me da un poquito de vergüenza decirlo... yo pasé con mochila, porque al menos yo no tenía quién me echara la mano, y cuando yo llegué a Mexicali, los coyotes pedían de 4500 dólares, algo que yo no había visto, un dineral. Me quedé en Mexicali casi veinticinco días y ahí me encontré a unos hondureños. Me dijeron "vámonos a Caborca [Sonora] allá la hacemos. Yo conozco gente, yo pasé una vez y vamos a volver a pasar. Es más seguro ir con ellos que con un coyote.". Nos pagaron 500 dólares por pasar una mochila de 20 kilos caminando siete días en el desierto. Pero no sabíamos que trae adentro, nomás nos la dieron. Llevamos un guía y el lonchero que lleva pura comida y agua, y gracias a dios llegué bien. Nos dejaron en Phoenix [Arizona], ya nos estaba esperando una Van y ahí dejamos la mochila. Yo estaba feliz, pero a los cuatro meses y medio me deportaron. Y ahora voy de nuevo p'arriba, ya sé a quién voy a contactar (Francisco, 40 años, Amatlán de los Reyes, agosto de 2016).

La existencia de una prohibición legal genera a su alrededor un campo de prácticas ilegales (De Genova, 2002: 422 cit. en Foucault, 1979: 280). Las fronteras políticas son el germen de profundas desigualdades entre quienes son considerados con el derecho de pisar un suelo, y quienes se encuentran desprovistos de dichas atribuciones aun cuando su vida corra peligro en su lugar de origen. La mayoría de los entrevistados asegura también haber sufrido agresiones por parte de policías mexicanos, y señalan a miembros de los cuerpos policiacos como autores de atracos y extorsiones. Uno de ellos, procedente de Tegucigalpa, relató que agentes policiacos lo sorprendieron a bordo del tren al pasar por la ciudad de Córdoba, Veracruz; no lo lastimaron pero le pidieron dinero a cambio de dejarlo ir, mientras que a uno de sus compañeros lo despojaron de la mochila donde traía ropa y documentos oficiales.

Un caso similar fue el de Martín, hondureño de 23 años, quien una tarde de abril de 2015 fue detenido en una calle céntrica de Xalapa por agentes de la policía municipal y la fuerza civil. Según su narración, los oficiales arguyeron que tenía una actitud sospechosa y que se encontraba bajo el efecto de drogas, lo cual no pudieron demostrar. Fue liberado tras el pago de una multa. Noé, Nancy y Javier (todos hondureños) fueron detenidos en mayo de 2016, también en la ciudad de Xalapa, bajo la acusación de fumar marihuana en la vía pública, hecho que ellos negaron rotundamente. De igual manera que ocurrió a Martín, fueron liberados tras el pago de una multa, pero atemorizados decidieron alejarse de la ciudad por un tiempo. Se subieron al tren con rumbo al centro del país, donde permanecieron dos meses sobreviviendo del "charoleo"[4] en las calles y durmiendo en alojamientos precarios.

También acontece que los agentes del orden despojen a los migrantes del dinero que han logrado reunir mediante el "charoleo" en la vía pública, como lo expresó otro joven hondureño:

Los policías también te quitan el dinero, esos si son más gandallas [abusivos], esos no te van a encerrar dos días, tres días, quieren p'al refresco, ahora sí que son más ratas [ladrones] ellos, le roban a uno. Uno se gana la vida, la gente nos da la moneda y de corazón se agradece, hacemos artesanías, hacemos flores de aluminio con latas de refresco. Pero ellos no se fijan en eso y nos piden aunque sea veinte, 
treinta pesos, lo que hayamos juntado (Joven hondureño, Fortín, agosto de 2014).

Esteban, originario de Choloma-Honduras, relató que fue golpeado por policías en un crucero ubicado cerca de la zona universitaria de Xalapa a principios del año 2016, tras un altercado con una vendedora ambulante que lo increpaba para que se alejara de ese lugar, donde él se encontraba "charoleando". Según su relato, los policías acudieron al llamado del esposo de la mujer, quien lo acusó de ser de "marero"; lo amedrentaron con sus armas y lo golpearon en el tórax y el abdomen. Después de la golpiza, lo dejaron en libertad diciendo: "A ver si así aprendes a respetar a las mujeres o si no mejor te largas a tu país”. (Esteban, comunicación personal, febrero de 2016). En ningún momento la idea de la denuncia pasó por la mente de Esteban, asumiendo de manera natural su orfandad institucional y total desprotección.

Los migrantes indocumentados son siempre culpables de alguna infracción legal; su condición intensifica su sujeción a formas cotidianas de intimidación y amenaza. La ilegalidad es un estatus jurídico y una condición política que define una relación social con el Estado y la sociedad. Dicha condición puede ser vista como una clase de objeto etnográfico, útil para plantear una mirada crítica hacia las políticas migratorias de los estados-nación. Es por ello preciso desnaturalizar la "ilegalidad" de los migrantes y producir información etnográfica sobre los procesos políticos de la “ilegalización" (De Genova, 2002: 422-6).

1.3. Violencia simbólica. Con este término Burgois se refiere a las humillaciones y legitimaciones de desigualdad y jerarquía internalizadas, que incluyen desde el sexismo y el racismo hasta expresiones íntimas del poder de clase. El racismo, el desempleo, la explotación económica, alimentan la sensación de inferioridad entre los excluidos que se traduce en acciones de violencia auto-destructiva o comunal (2005: 31). La condición de "ilegalidad" conlleva un sufrimiento emocional vinculado al alejamiento del entorno de socialización primaria y de las redes de apoyo sociales y familiares (Fragoso, 2016). En este sentido, la movilidad se torna en la práctica significante que señala la diferencia y marca los límites simbólicos con los otros.

La noción de violencia simbólica también ha sido desarrollada por Bourdieu, para develar cómo se ejerce la dominación a un nivel íntimo por parte de los dominados, quienes colaboran en su propia opresión cada vez que persiguen y juzgan el orden social a través de categorías que hacen que éste parezca natural y evidente por sí mismo (Bourdieu y Wacquant, 1992, cit. en Burgois, 2005: 13). Los migrantes hondureños se enfrentan a diario a este tipo de violencia, como expresó un hombre de mediana edad que se encontraba en Xalapa, en camino a Nuevo Laredo, Tamaulipas: "Aquí la gente es muy espantada. Venía una muchacha con un niño, ¡Corre, corre! le dijo, ¡De aquél lado!, como si yo le fuera a robar. Ando tisiado, tatuado pues, luego la gente es más desconfiada" (Xalapa, 17 de junio de 2016).

Christian, otro joven hondureño expresa:

Hacemos figuras de palma porque no nos gusta andar pidiendo así con la mano vacía, porque luego la gente se aparta. Nada más se le acerca uno y lo primero que hacen es agarrar su bolsa. Les digo, no se espante madrecita, no le vamos a robar... (Fortín, Agosto de 2014).

Damián, originario de La Ceiba, Honduras, tiene alrededor de 30 años y pide apoyo económico llevando de la mano a su hija de unos nueve años de edad. Se dirige a los automovilistas que disminuyen la velocidad para pasar un tope o detenerse en el semáforo: "Una moneda, mexicano, con lo que podás, es para mi niña. Con todo respeto, dios te bendiga. Gracias, bendiciones". Esta escena anima reacciones de solidaridad; varios automovilistas le entregan 
monedas que él agradece. Sin embargo, algunas personas lo increpan porque consideran haraganería el acto de pedir dinero en la vía pública, no saben que Damián ha trabajado eventualmente en Xalapa como ayudante de albañil por un raquítico sueldo de 500 pesos semanales. Este salario representa al menos la mitad de lo que obtiene un mexicano por las mismas horas de trabajo, por ello alterna esta actividad con el "charoleo" en la vía pública, donde puede obtener mejores ingresos movilizándose estratégicamente de un lado a otro de la ciudad y de la región.

La violencia simbólica responde a una lógica que se fija en la trama social del contexto migratorio irregularizado, en la cual el migrante se inserta y se identifica a sí mismo. La condición de exclusión y marginalidad precisa el aprendizaje continuo de los fundamentos para desenvolverse en un entorno hostil tanto material como simbólicamente. Se requiere del ejercicio renovado de la supervivencia en medio de múltiples carencias y tensiones de carácter material, social, afectivo y simbólico.

1.4. Para Burgois, la violencia cotidiana consiste en las prácticas y expresiones diarias de violencia en un nivel micro-interaccional, interpersonal, doméstico y delincuencial. Retoma este concepto de la formulación de Scheper-Hughes (1992, 1996) para centrarse en las experiencias vividas que normalizan las pequeñas brutalidades y terror de la comunidad y crea un sentido común o ethos de violencia. Se ha usado el concepto de violencia cotidiana para llamar la atención a un nivel fenomenológico sobre los "crímenes en épocas de paz", las "pequeñas guerras" y los "genocidios invisibles" que afectan a los pobres de todo el mundo (Scheper-Huges, 1996, 1997). Pero Burgois considera más útil limitar la noción a las prácticas y expresiones de agresión interpersonal rutinarias que sirven para normalizar la violencia a un nivel micro, como pueden ser el conflicto doméstico, delictivo y sexual, e incluso el abuso de sustancias. Este tipo de violencia puede crecer y cristalizar en una "cultura del terror", en una normalización de la violencia tanto en la esfera pública como en la privada. Burgois señala que el conflicto interpersonal y la autodestrucción tienen un efecto políticamente desmovilizador e impiden la construcción de comunidad.

La violencia intra-grupal, el robo entre compañeros, el abandono continuado de viviendas y posesiones, el consumo de alcohol, enervantes e inhalantes, son expresiones de la interrelación de pobreza, segregación, exclusión y orfandad institucional que proporciona el contexto para la participación en economías ilegales y otras formas de criminalidad (Agudo, 2017). Los migrantes en tránsito o "atrapados en la movilidad" oscilan en un péndulo constante entre estar bajo amenaza -de ser deportados, asaltados, golpeados- a ser ellos mismos fuente de amenaza real o simbólica. En ocasiones, recurren a la violencia hacia el Otro (pobladores locales) y/o hacia los miembros de su propio grupo.

¿Cómo podrían construir comunidad bajo este continuum de violencia que más bien genera desagregación social? Muchos de ellos viven a "salto de mata", moviéndose de un lugar a otro, permaneciendo por periodos de tiempo indefinidos en diferentes localidades. Xalapa, Córdoba, Orizaba, Fortín, entre otras, son ciudades de la región central de Veracruz donde se establecen transitoriamente -y en algunos casos de manera definitiva- alojándose en asentamientos urbanos segregados, hacinados en vecindades, donde son partícipes del "triángulo de la violencia": victimarios, víctimas y testigos (Riches, 1988, cit. en Feixa y Ferrándiz, 2005: 212).

ElcasodeAldo, unjovenhondureñodeaproximadamente veinte años de edad, es una desafortunada muestra de ello. Tras haber salido de San Pedro Sula en el año 2014, se dedicó a viajar por tramos por el corredor del Golfo de México en dirección a la frontera noreste 
del país. Al llegar a Reynosa, Tamaulipas, constató las dificultades para llegar a Estados Unidos y los peligros de ser secuestrado o reclutado por los cárteles del crimen organizado que operan en la zona. Decidió regresar hacia el sur, donde supuso que tendría mejor suerte. En el camino conoció a otros dos jóvenes de su país con quienes llegó a Xalapa. Tenían información de que se trataba de una ciudad tranquila, en la cual no existen demasiados probabilidades de ser acosado por el crimen organizado ni por las autoridades migratorias. Al igual que sus paisanos, Aldo se dedicó a "charolear", con lo que recolectaba podía solventar sus gastos mínimos de supervivencia.

Una mañana de mayo de 2016, se presentó en uno de los puntos de la ciudad donde él y otros paisanos suelen ubicarse para colectar dinero. Mostraba evidentes huellas en su rostro y cuerpo de haber recibido una severa golpiza. Según su relato, había sido asaltado y golpeado tres noches atrás mientras se dirigía al cuarto de vecindad que alquilaba en la colonia Las Torres. Regresaba de la ciudad de Puebla, donde había permanecido "charoleando" durante varios días. Según su versión, el autor intelectual del ataque fue su propio hermano, Agustín, de 16 años, quien había llegado desde Honduras apenas un par de semanas antes y sabía de la hora en que Aldo regresaría a casa con el dinero reunido. Según sus conjeturas, su hermano se coludió con otros jóvenes (también hondureños) quienes lo esperaron cerca de su vivienda, para despojarlo del pequeño capital recién adquirido y las demás pertenencias que llevaba consigo. Después del hecho, Agustín y sus cómplices desaparecieron de la ciudad. Semanas más tarde, Aldo se enteró de que su hermano menor había sido deportado y se encontraba ya con su familia en San Pedro Sula.

Un caso aún más estremecedor es el de Walter. En el 2015 tenía cuarenta años y doce de permanencia en el estado de Veracruz. De acuerdo con su narrativa, recopilada a lo largo de repetidas conversaciones,
Walter emigró de Honduras después de cumplir una condena en la cárcel en Tegucigalpa. Pertenecía a una clicka y estuvo acusado de homicidio. Llegó al estado de Veracruz a bordo de La Bestia y se estableció por un tiempo en la ciudad de Tierra Blanca, uno de los puntos importantes de la ruta del Golfo de México. Ahí se involucró en actividades ilegales y vivió en unión libre con una mujer veracruzana. Al cabo de unos años decidió salir de ese lugar, a causa de altercados con agrupaciones pandilleras locales y por encontrarse en la mira de las autoridades. En Xalapa se dedicaba a la venta ambulante de golosinas, así como de figuras de palma y de aluminio reciclado. Solía consumir cerveza, mariguana y otras sustancias, llevaba tatuajes en distintas partes de su cuerpo y cicatrices de heridas con armas punzocortantes, resultado de peleas callejeras.

Un día Walter apareció en el punto habitual severamente lastimado, con vendajes en la cabeza y en una de sus piernas. De acuerdo con su relato, había estado internado en la Cruz Roja tras un ataque a machetazos por parte de un grupo de sujetos de su vecindario, con quienes se había enemistado. Se salvó de milagro y siguió apareciendo eventualmente en los lugares de "charoleo", hasta que se hizo notar su ausencia. Pasaron varias semanas antes de que circulara el rumor de que había sido asesinado, y que su cuerpo sin vida había aparecido cerca de su vivienda, en las inmediaciones de las vías del tren, una madrugada de octubre del 2016.

\section{Comentario final}

Como hemos visto, las experiencias de vida de los migrantes hondureños en tránsito o "atrapados en la movilidad" en las localidades veracruzanas, aluden a las diferentes dimensiones de la violencia propuestas por Burgois, las cuales no se excluyen ni se contraponen. El campo de la violencia en el que se insertan a lo largo de sus vidas no puede reducirse a un análisis clasificatorio, ni tampoco a explicaciones generalizadoras de orden 
macro-estructural. Es por ello que en este artículo se ha tratado de mostrar las conexiones entre lo estructural y lo cotidiano, entre la violencia física y la violencia simbólica, a partir de breves atisbos a las vivencias de algunos de los entrevistados. Como señala nuestro autor, el reto de la etnografía es esclarecer las cadenas de causalidad que unen la violencia estructural, política y simbólica con la producción de la violencia cotidiana. Dicho continuum de violencia sostiene las relaciones sistémicas de poder desiguales (Burgois, 2005: 32).

La documentación de la violencia política y estructural no debe soslayar la observación de la violencia cotidiana en un nivel micro-interaccional que, en muchos casos, limita las posibilidades de construcción de comunidad. La función del etnógrafo es precisamente buscar las marcas de la violencia estructural y política sobre las personas, sus cuerpos y su entorno inmediato (Feixa y Ferrándiz, 2005: 213).

La migración indocumentada supone un claro desafío para los Estados nacionales, ya que evidencia la ineficacia de los controles fronterizos. Este fenómeno demuestra la coexistencia de distintas vías que combinan dispositivos legales e ilegales que posibilitan la internación de personas sin documentos a través de los límites nacionales (Alvarez, 2011: 11, cit. en Sassen, 2001). Durante el trayecto como indocumentados, así como en el lugar de destino, los migrantes viven una experiencia de desamparo; al no ser sujetos del estado de derecho permanecen en "estado de excepción" (Agamben, 2005).

Gran parte de las personas entrevistadas en el curso de esta investigación, han desistido del "sueño americano" y su deseo es establecerse en México de manera legal. Aspiran a contar con posibilidades de acceso a mejores condiciones de vida, a obtener un empleo que les permita acabar con la incertidumbre y el peligro que caracteriza su día a día. En las condiciones actuales, muchos de ellos se enfrentan a la exclusión social y a las distintas formas de violencia arriba descritas, aunadas a la falta de capital cultural y simbólico indispensable para emprender un proyecto de vida en el contexto migratorio.

Frente a estas paradojas y contradicciones, es preciso indagar y enfrentar las causas estructurales que causan el desplazamiento y migración irregularizada en los lugares de origen. Pero también es urgente impugnar la naturalización de la violencia hacia los migrantes que permanecen o atraviesan el territorio mexicano, así como transformar las formas de acceso al empleo legal y los mecanismos de regularización migratoria.

\section{Bibliografía}

Abarca, H. y M. Sepúlveda (2005): "Barras bravas, pasión guerrera. Territorio, masculinidad y violencia en el fútbol chileno", en Ferrándiz, F. y C. Feixa, eds., Jóvenes sin tregua. Culturas y políticas de la violencia. Barcelona, Anthropos Editorial, pp. 145-170.

Agamben, G. (2005): Estado de excepción. Homo sacer, II, I. Buenos Aires, Adriana Hidalgo editora.

Aguilar, J. y M. Carranza (2008): "Las Maras y pandillas como actores ilegales de la región”, en Informe Estado de la Región. Un informe desde Centroamérica y para Centroamérica, San Salvador, IUDOP.

Álvarez Velasco, S. (2016): Frontera sur chiapaneca. El muro humano da la violencia. Análisis de la normalización de la violencia hacia los migrantes indocumentados en tránsito. Universidad Iberoamericana, México.

Álvarez Velasco, S. (2016b): Migración indocumentada en tránsito: la cara oculta de los 
procesos migratorios contemporáneos, Buenos Aires, CLACSO, Serie Documentos de Trabajo, Red de Posgrados, Documento no. 10.

Álvarez Velasco, S. (2017): “Etnografías y violencias en comunidades en movimiento $\mathrm{y}$ circulación migratoria. Legados de la primera inmersión en el campo. Desmantelando preconcepciones del sentido común, la selectividad nacionalista, y politizando la etnografía del tránsito migratorio irregularizado", en Castro Neira, Y. y A. Blazquez, Coords., Micropolíticas de la violencia. Reflexiones sobre el trabajo de campo en contextos de guerra, conflicto y violencia, México, Cuadernos de Trabajo de MESO, N5, pp. 45-59.

Agudo Sanchíz, A. (2017): “Autoetnografía de un misionero antropológico en las políticas de seguridad", en Castro Neira, Y. y A. Blazquez, Coords., Micropolíticas de la violencia. Reflexiones sobre el trabajo de campo en contextos de guerra, conflicto y violencia, México, Cuadernos de Trabajo de MESO, N5, pp. 98-112.

Arriola Vega, L. A. (2012): "Migrantes centroamericanos en transitoriedad: hondureños en Tabasco, México", en Ana María Aragonés, A. M., coord., Migración Internacional. Algunos Desafíos, México, UNAM, pp. 193-216.

Becker, H. (2009): Outsiders. Hacia una sociología de la desviación, Buenos Aires, Siglo XXI editores.

Bourdieu, P y L. Wacquant (1992): An invitation to reflexive sociology, Chicago, University of Chicago Press.

Bourdieu, P. (1997): Pascalian Meditations,
Stanford, Stanford University Press.

Burgois, P. (2005). "Más allá de una pornografía de la violencia. Lecciones desde El Salvavador", en Ferrándiz, F. y C. Feixa, eds., Jóvenes sin tregua. Culturas y políticas de la violencia, Barcelona, Anthropos Editorial , pp. 11-34.

Calderón Chelius, L. (2016): “Las organizaciones de la sociedad civil ante la migración en tránsito en México", Guadalajara, CANAMID Policy Brief Series, PB13, CIESAS. Disponible en web: www.canamid.org. Consultado el 14 de abril de 2017.

Castañeda,A. (2015): Reporte: Programa frontera sur o la política de persecución de migrantes en México. Observatorio de Legislación y Política Migratoria, México, COLEF-Comisión Nacional de los Derechos Humanos.

Cobo, S. y P. Fuerte (2012): Refugiados en México. Perfiles sociodemográficos e integración social, México, SEGOB/Centro de Estudios Migratorios/INM/COMAR.

Comisión Nacional de Derechos Humanos (2009): Diagnóstico de las condiciones de vulnerabilidad que propician la trata de personas en México, México, Centro de Estudios e Investigación en Desarrollo y Asistencia Social.

Comisión Nacional de Derechos Humanos (2011): Informe especial sobre secuestro de migrantes en México, disponible en web: www. cndh.org.mx/node/35. Consultado el 28 de enero de 2017.

De Genova, N. (2002): “Migrant 'illegality' and deportability in everyday life", Annual Review of Anthropology, vol. 31, pp. 419-447. 
De Genova, N. (2004): “The legal production of Mexican / migrant illegality", Latinos Studies, vol. 2, pp. 160-185.

FAO, UN-HABITAT (s/f): "La amenaza hidrometeorológica en Honduras" en: En Tierra Segura. Desastres naturales y tenencia de la tierra. Honduras, FAO, UN-HABITAT, pp. 1-12

Fernández Casanueva, C. (2014): "Vivir y trabajar en la ciudad de Tapachula, Chiapas: el caso de inmigrantes hondureños", en Rivera Farfán, C., coord., Trabajo y vida cotidiana de centroamericanos en la frontera suroccidental de México, México, CIESAS, pp. 197-226.

Fernández Casanueva, C. y M. T. Rodríguez (2016): "Hondureños migrantes en México: del tránsito al asentamiento", Guadalajara, CANAMID Policy Brief Series, PB11. Disponible en: www.canamid.org. Consultado el 30 de enero de 2017.

Feixa, C. y F. Ferrándiz (2004): "Epílogo. Jóvenes sin tregua", en Ferrándiz, F. y C. Feixa, eds., Jóvenes sin tregua. Culturas y políticas de la violencia, Barcelona, Anthropos Editorial, pp.209-233.

Ferrándiz, F. y C. Feixa (2004): "Una mirada antropológica sobre las violencias", en Alteridades, UAM-Iztapalapa, México, No. 14, pp. 159-174.

Fragoso Lugo, P. O. (2016): A puro golpe. Violencias y malestares sociales en la juventud cancunense, México, UNICACH/CESMECA/ UNAM

Goffmann, E. (2001): Estigma. La identidad deteriorada, Buenos Aires, Amorrortu Eds.

González Cerdeira, Y. (2014): “Centroamérica: ¿Y quiénes son los que se van? Volvamos la vista al sur. El caso de Honduras", en Migrantes invisibles, violencia tangible. Informe 2014. Red de Documentación de las Organizaciones Defensoras de Migrantes, México, Ed. Letra Impresa GH, S.A. de C.V, pp.46-57.

InSight Crime. (2015): Maras y pandillas en Honduras, InSigth Crime, Asociación para una Sociedad más Justa.

Llanes Salazar, R. (2017): "Arendt, los otros muros y la escoria de la tierra", https://ceasmexico. wordpress.com/2017/02/17/ Consultado el 18 de febrero de 2017.

Martel Trigueros, R. (2007): "Las maras salvadoreñas: nuevas formas de espanto y control social", en Valenzuela Arce, J. M., A. Nateras y R. Reguillo, coords., Las Maras: Identidades juveniles al límite, México, UAM-Iztalapala/ COLEF, pp. 83-125.

Nail, T. (2015): The figure of the migrant, Stanford, Stanford University Press.

Pérez, O. J. y E. J. Zechmeister (2014): Cultura política de la democracia en Honduras y en las Américas, 2014: Gobernabilidad democrática a través de 10 años del Barómetro de las Américas, FOPRIDEH, LAPOP, Hagamos Democracia, Barómetro de las Américas, Vanderbilt University.

Porraz Gómez, I.F.(s/f): "Entender las violencias: Los jóvenes migrantes centroamericanos en sus lugares de origen y su tránsito por el sur de México", Mcs.

Reguillo, R. (2007): "La mara: contingencia y afiliación en el exceso (re-pensando los límites", en Valenzuela Arce, J. M., A. Nateras y R. Reguillo, coords., Las Maras: Identidades juveniles al límite, México, UAM-Iztalapala/ COLEF, pp. 307-322. 
Riches, D. (ed.) (1988): El fenómeno de la violencia, Madrid, Ed. Pirámide.

Rivas Castillo, J. (2014): “Trayectorias emergentes, historias recurrentes. Inmigrantes salvadoreños en el Soconusco, Chiapas", en Rivera Farfán, C., coord., Trabajo y vida cotidiana de centroamericanos en la frontera suroccidental de México, México, CIESAS, pp. 169-195.

Rodríguez Chávez, E. (2016). "Migración centroamericana en tránsito irregular por México: nuevas cifras y tendencias", Guadalajara, CANAMID Policy Brief Series, PB14, CIESAS. Disponible en: $\underline{w w w . c a n a m i d . o r g}$ Consultado el 5 de marzo de 2017.

Rodríguez Herrero, H. (2016). "Gubernamentalidad y violencia hacia los migrantes en el corredor del Golfo de México", Guadalajara, CANAMID Policy Brief Series, PB12, CIESAS. Disponible en: www.canamid. org Consultado el 12 de marzo de 2017.

Sassen, S. (2001): ¿Perdiendo el control? La soberanía en la era de la globalización, Barcelona, Ed. Bellaterra.

Sassone, S. (2010): "Migraciones, metropolización y transnacionalismo. Entre América Latina y Europa", en Curso 1015, CLACSO.

Scheper-Hughes, N. (1992). Death without weeping: the violence of everyday life in Brazil, Berkeley, University of California Press.

Scheper-Hughes, N. (1996). "Small Wars and Invisible Genocides", Social Sciences and Medicine, 43 (5), pp. 889-900.

Scheper-Hughes, N. (1997): "Peace-Time Crimes", Social Identities, 3 (3), pp. 471-497.
Salazar, S. (2017). “Afectividad y violencia. Reflexiones en torno a una experiencia de trabajo de campo en Honduras y el sur de México", en Castro Neira, Y. y A. Blazquez, coords., Micropolíticas de la violencia. Reflexiones sobre el trabajo de campo en contextos de guerra, conflicto y violencia, México, Cuadernos de Trabajo de MESO, N5, pp. 72-84.

Shoshan, N. (2015). "Más allá de la empatía: escritura etnográfica de lo desagradable", Nueva Antropología, México, Vol. 28, No. 83.

Serrano, J.F. (2005): “La cotidianidad del exceso. Representaciones de la violencia entre jóvenes colombianos", en Ferrándiz, F. y C. Feixa, eds., Jóvenes sin tregua. Culturas y políticas de la violencia. Barcelona, Anthropos Editorial, pp.129-144.

Valenzuela Arce, J. M. (2007): "La mara es mi familia”, en Valenzuela Arce, J. M., A. Nateras y R. Reguillo, coords., Las Maras: Identidades juveniles al límite, México, UAM-Iztalapala/ COLEF, pp. 33-61.

Recibido: 30 de octubre de 2017

Aceptado: 03 de enero de 2018 


\section{NOTAS}

[1] Los estados mexicanos de Chiapas y Tabasco han estado ligados al flujo migratorio centroamericano, a causa de la movilidad laboral transfronteriza y debido a los conflictos políticos que dieron lugar al desplazamiento de refugiados guatemaltecos y salvadoreños en la década de los setentas y ochentas (Rivas, 2016 y Fernández Casanueva, 2016; entre otros).

[2] InShigt Crime define a una mara o pandilla como "un grupo de personas -usualmente jóvenes y de origen socioeconómico bajo- compuesto por células relativamente autónomas, claramente identificables. Estas células se definen a sí mismas, parcialmente, por una violencia constante y recíproca contra otros grupos juveniles; y además de ser el medio para establecer jerarquías internas y asignar poder y estatus, es precisamente este conflicto lo que las convierte en organizaciones cohesivas" (2015: 13).

[3] Los nombres reales de los entrevistados han sido sustituidos por seudónimos para proteger su identidad.

[4] Se conoce coloquialmente como "charolear" a la actividad de solicitar dinero en las calles a transeúntes y automovilistas. 